\title{
Study on pain, quality of life and disability relation in patients with degenerative cervical spine disorders
}

\author{
Silişteanu Sînziana Călina MD, Antonescu Elisabeta, Physicist, PhD \\ "Ştefan cel Mare" University, Suceava, "Lucian Blaga" University of Sibiu
}

\section{Introduction}

Degenerative diseases rank third in the world after cardiovascular and oncologic diseases. Degenerative diseases of the cervical spine are characterized by chronic pain, limited cervical mobility and radiation to the neck and shoulder, upper limb or the skull with dynamic cervical disorders. The highest frequency of such events is found in the age group of 40-50 years old, leading to reduced working capacity and absenteeism. Prevalence of the disease increases with age. Substrate of these events is particularly represented by joint degenerative processes and postural changes of the cervical spine. The study aims at presenting the relationship between pain, disability and quality of life in patients with cervical spondylosis.

\section{Materials and methods}

The study was conducted over a period of five months on a sample of 126 ambulatory patients ( 72 women and 54 men). Patients were divided into two groups: G1 followed medication (painkillers, anti-inflammatory drugs, sedatives, muscle relaxants, neurotropic drugs), massage and physiotherapy, and in group G2, electrotherapy (low and medium frequency currents, ultrasound), massage and kinesiology were applied. Evaluation of patients was made at the beginning and at the end of treatment, 10 days later.

Criteria for inclusion of patients in the study: age 30-75 years old, the presence of pain and functional syndrome at cervical spine level, patients' consent to participate in the trial and the possibility of evaluation during the application of the treatment.

Exclusion criteria were: age $<30$ years old and $>75$ years old, disorders associated with decompensated stage, tumour type pain or caused by trauma and the lack of cooperation to apply the treatment.
Visual analogue scale (VAS) was used for the subjective, yet quantified assessment of pain (the scale was filled out by the patient). VAS allows the quantitative measurement of a subjective symptom (pain), which is an entirely personal experience. It is used for pain monitoring over time, in a same patient or its evolution in a group of patients.

To assess quality of life, the quantified QOL scale was used. This allows health status assessment based on the recovery programme applied. The scale contains questions regarding the patient's social and family issues, work and leisure, emotions and capacity to solve health problems.

For disability, "Cervical disability index" ("neck disability") was used, which is a form of Oswestry scale adapted for the patients with pain in cervical spine and with a major impact on quality of life. This scale contains 10 items referring to pain, personal care, social and professional activities, leisure activity, sleep.

Distribution of patients by age and gender is shown in the charts below: 


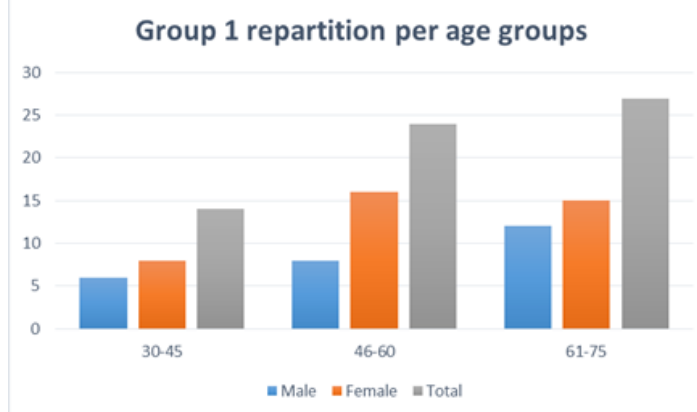

Low and medium frequency currents are easily tolerated by patients and have been used for pain relief and muscle relaxation. There were used diadynamic current (sinusoidal, low frequency, transformed in DF, considered having the highest analgesic effect, at a frequency of $100 \mathrm{~m} / \mathrm{s}$ and PL variant of PS, when the transformation from MF in DF and vice versa is made slowly, predominating the analgesic and muscle relaxant effects), Trabert current, TENS (pulse frequency being between $15-500 \mathrm{~Hz}$ with a duration of, $15-500 \mu \mathrm{s}$ and 10 minutes) and the interferential current.

Ultrasound was applied to the points of maximum pain intensity, on the contracted muscles. Ultrasounds are mechanical oscillations of an environment with plastic properties, these oscillations having frequencies higher than the frequency of the sound. Pulsating form was used to reduce the deep thermal effects of the continuous form, with a frequency of $1 \mathrm{MHz}$ and intensity of $0,7 \mathrm{~W} / \mathrm{cm}^{2}$ in daily application.

The massage included sedative, analgesic, muscle relaxation, smoothness,

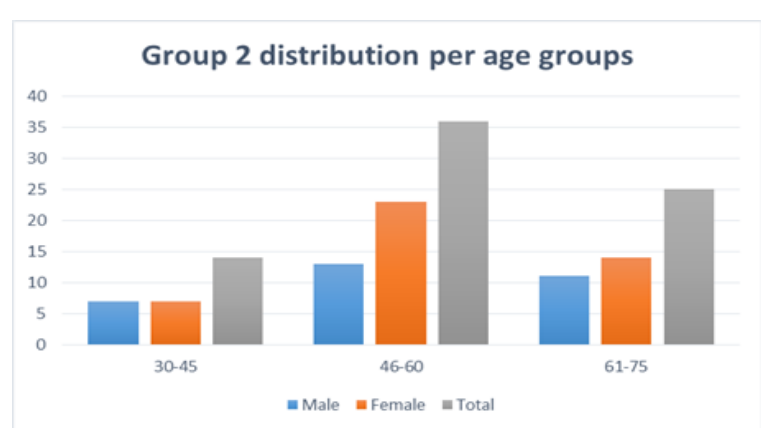

hyperemic techniques, friction, vibrations, punctiform pressure massage.

Physical therapy programme aimed at performing passive motion with small amplitude and speed of execution, mild tractions in cervical axis, assisted active exercises, simple active activities or with resistance to correct mobility disorders. Special attention was paid for the performance of postures to correct the static disorders and in order to restore the normal tonus of cervical muscle through asuplisation exercises, muscle stretching techniques and tonification of hypotonic flexor muscle.

For the statistical analysis of the obtained data, median, standard deviation and Student's t-test were used.

\section{Results}

For the VAS scale, in G1 and G2 groups, there can be noticed a reduction of the initial and final values for median and standard deviation.

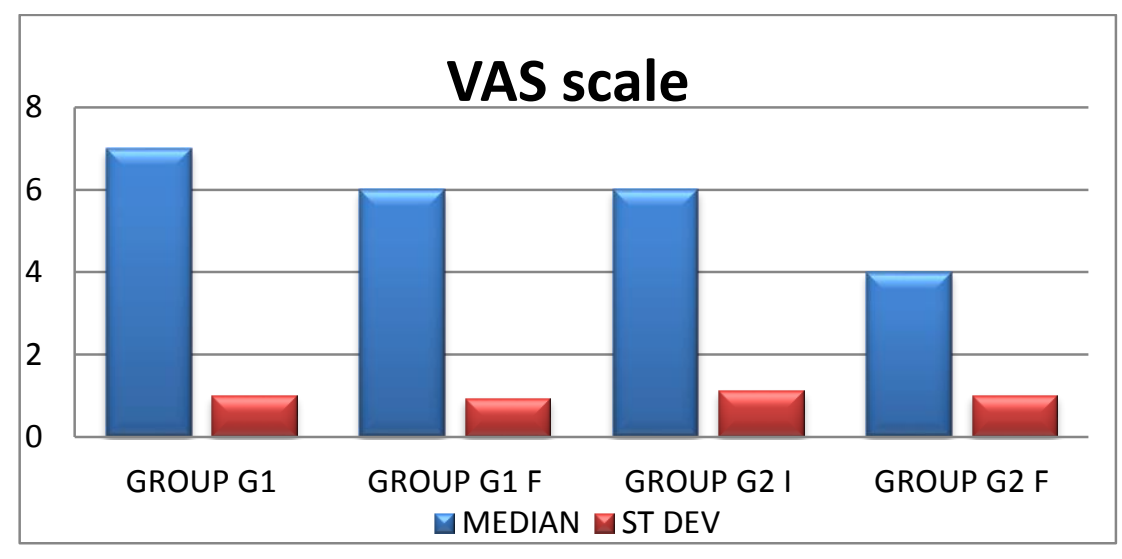


For quality of life index, there was noticed an increase of the median values and decrease of standard deviation values.

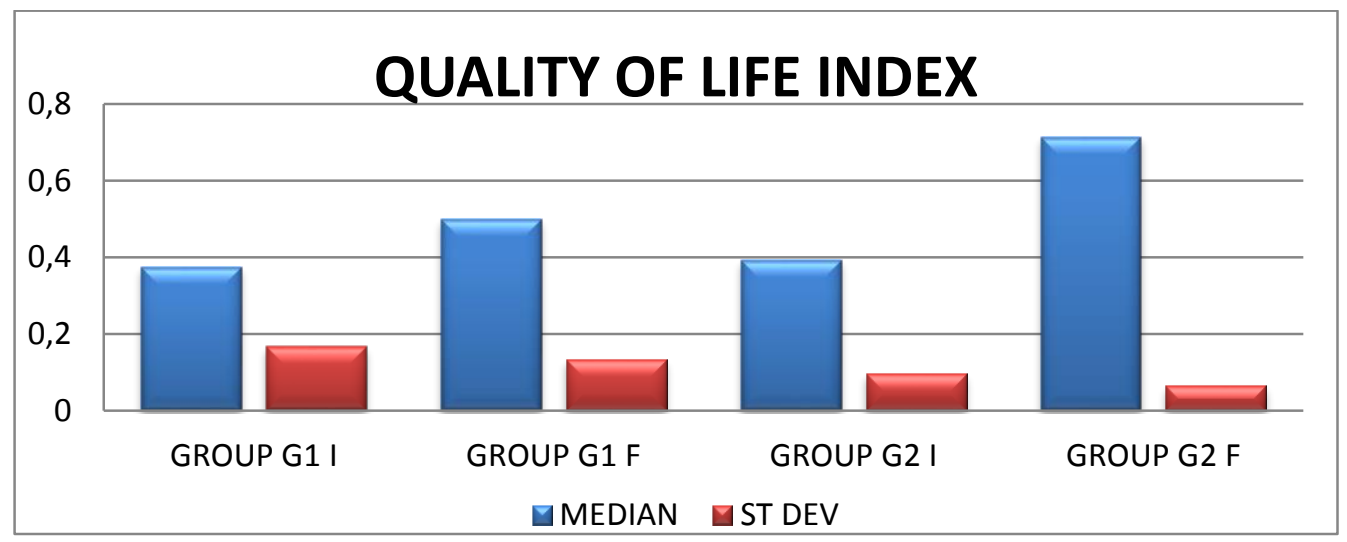

Neck disability index shows a reduction of the values in both groups, both for median and standard deviation.

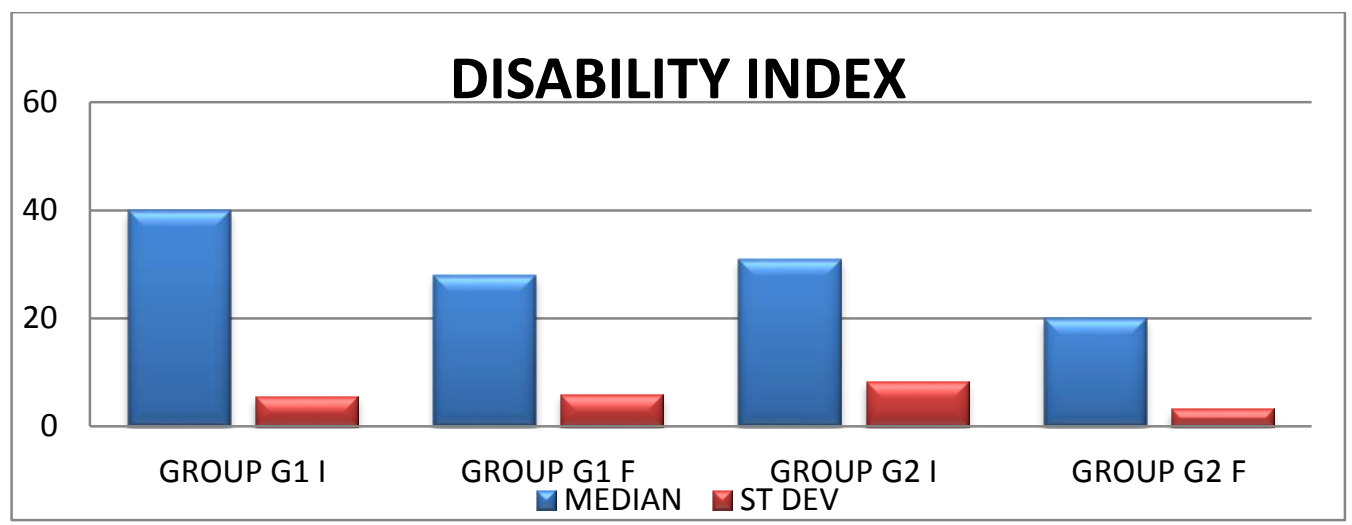

\begin{tabular}{|l|l|l|}
\hline & GROUP G1 & GROUP G2 \\
\hline$t$ test VAS & 0.004043 & 0.02955 \\
\hline$t$ test ICV & 0.023601 & 0.04996 \\
\hline$t$ test IDC & 0.021159 & 0.04089 \\
\hline
\end{tabular}

Student $\mathrm{t}$ test for VAS scale shows statistically highly significant values for G1 and statistically significant for the G2 group.
For quality of life index, the results are statistically significant, as well as for neck disability index. 


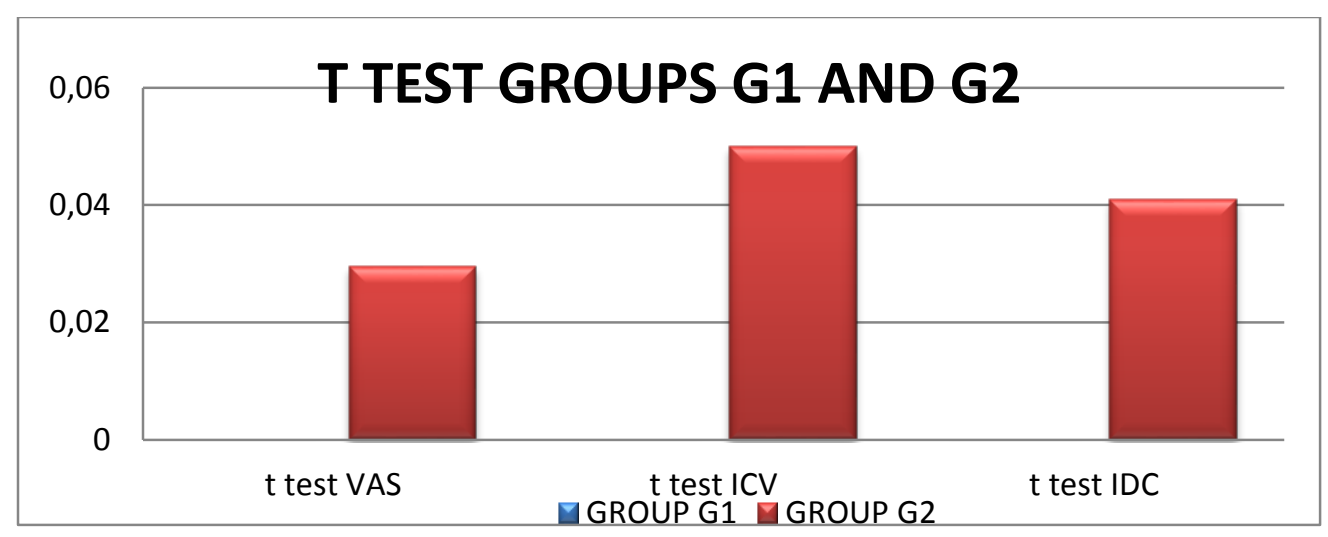

\begin{tabular}{|l|l|l|l|l|}
\hline \multirow{2}{*}{ Scale } & Groups & \multicolumn{2}{|l|}{ Median and standard deviation } & p \\
\cline { 3 - 5 } & & Initial & Final & \\
\hline VAS & G1 & $\mathbf{7} \pm \mathbf{0 . 9 9 3 2}$ & $\mathbf{6} \pm \mathbf{0 . 9 3 5 9}$ & $\mathbf{0 . 0 0 4} \mathrm{S}$ \\
\cline { 2 - 5 } & G2 & $\mathbf{6} \pm \mathbf{1 . 1 1 9 1}$ & $\mathbf{4} \pm \mathbf{1 . 0 1 1 9}$ & $\mathbf{0 . 0 2 9} \mathrm{S}$ \\
\hline \multirow{2}{*}{ ICV } & G1 & $\mathbf{0 . 3 7 5} \pm \mathbf{0 . 1 6 7 0}$ & $\mathbf{0 . 5} \pm \mathbf{0 . 1 3 3 0 9}$ & $\mathbf{0 . 0 2 3} \mathrm{S}$ \\
\cline { 2 - 5 } & G2 & $\mathbf{0 . 3 9 2} \pm \mathbf{0 . 0 9 5 6 7}$ & $\mathbf{0 . 7 1 4} \pm \mathbf{0 . 0 6 5 6}$ & $\mathbf{0 . 0 4 9} \mathrm{S}$ \\
\hline IDC & G1 & $\mathbf{4 0} \pm \mathbf{5 . 6 2 2 2}$ & $\mathbf{2 8} \pm \mathbf{5 . 8 9 6 9}$ & $\mathbf{0 . 0 2 1} \mathrm{S}$ \\
\cline { 2 - 5 } & G2 & $\mathbf{3 1} \pm \mathbf{8 . 2 1 4 7}$ & $\mathbf{2 0} \pm \mathbf{3 . 3 3 2 2}$ & $\mathbf{0 . 0 4 0} \mathrm{S}$ \\
\hline
\end{tabular}

\section{Conclusion}

After the application of treatment, statistical significant results were found in G2 for the aimed parameters: pain, quality of life and disability. The application of a complex treatment of electrotherapy, massage and physical therapy reduces pain with favourable consequences on quality of life and disability. The patient can quickly return to the daily activities. Treatment should be individualized according to patient and the stage of disease.

\section{References}

1. Lucescu V.- "Afectiunile degenerative ale coloanei vertebrale-Clinica, diagnosticul și tratamentul de recuperare"-Constanţa, Ed Dobrogea, 2009

2. Onose G.-“"Recuperare, Medicină Fizică și Balneoclimatologie-noțiuni de bază și actualităţi”, vol I Ed Medicală, București, 2008 3. Onose G, Pădure L.(Ed Coord)-“Compendiu de Neuroreabilitare la adulți, copii și vârstnici”. Ed Universitară Carol Davila, București, 2009
4. Păun R.(Ed Coord)-“ Tratat de Medicină Internă-Reumatologie”, vol I, Ed Medicală. București, 1999

5. Elisabeta Antonescu, Silişteanu Sînziana - Study On The Influence Of Ultrasound Intensity In Chronic Back Pain Treatment, Acta Medica Transilvanica, V. II, No.2, 2012, ISSN 1453-1968

6. Elisabeta Antonescu, Sînziana Călina Silişteanu, Clinical-Statistical Study On The Effectiveness Of Ultrasound Combined With Laser In Outpatient Treatment, Journal of International Scientific Publications: Materials, Methods and Technologies Volume 8, ISSN 1314-7269 (Online) 